\title{
Nanoparticles Preparation Using Microemulsion Systems
}

\author{
Anna Zielińska-Jurek, Joanna Reszczyńska, \\ Ewelina Grabowska and Adriana Zaleska \\ Gdansk University of Technology \\ Poland
}

\section{Introduction}

A wide range of techniques have been developed for the preparation of nanomaterials. These techniques include physical methods such as mechanical milling (Arbain et al., 2011) and inert gas condensation (Pérez-Tijerina et al., 2008), along with chemical methods such as chemical reduction (Song et al., 2009), photochemical reduction (Ghosh et al., 2002), electrodeposition (Mohanty, 2011), hydrothermal (Hayashi \& Hakuta, 2010), and sol-gel synthesis (Sonawane \& Dongare, 2006). Among all chemical methods the microemulsion has been demonstrated as a very versatile and reproducible method that allows to control over the nanoparticle size and yields nanoparticles with a narrow size distribution (LopezQuintela, 2003).

Microemulsions are homogeneous in macroscale and microheterogeneous in nanoscale dispersion of two immiscible liquids consisting of nanosized domains of one or both liquids in the other, stabilized by an interfacial film of surface active molecules. The essential distinction between normal emulsion and microemulsion is their particle size and stability. Normal emulsions age by coalescence of droplets and Ostwald ripening. Microemulsions are thermodynamically stable, single optically isotropic and usually form spontaneously. Microemulsions have ultralow interfacial tension, large interfacial area and capacity to solubilize both aqueous and oil-soluble compounds. Depending on the proportion of various components and hydrophilic-lypophilic balance (HLB) value of the used surfactant microemulsions can be classified as water-in-oil (W/O), oil-in-water $(\mathrm{O} / \mathrm{W})$ and intermediate bicontinuous structural types that can turn reversibly from one type to the other. The dispersed phase consists of monodispersed droplets in the size range of 5 $100 \mathrm{~nm}$. The nanodroplet size can be modified by varying concerned parameters, e.g. the type of stabilizer, continuous phase, the precursor content dissolved within the nanodroplets, and the water content, referred to as molar ratio of water to surfactant $(W)$. In addition the stability of the microemulsion can be influenced by addition of salt, concentration of reagents, temperature or pressure.

This chapter focuses on nanoparticles preparation using a microemulsion method, which has been employed for the preparation of particles from a diverse variety of materials, including metals (Pt, Pd, Ir, $\mathrm{Rh}, \mathrm{Rh}, \mathrm{Au}, \mathrm{Ag}, \mathrm{Cu}$ ) (Capek, 2004), silica and other oxides (Lee 
et al., 2005; Fu \& Qutubuddin, 2001), polymers (Krauel et al., 2005), semiconductors (Pinna et al., 2001), superconductors (Kumar et al., 1993) and bimetallic nanoparticles (Pt/Pd, $\mathrm{Pt} / \mathrm{Ru}, \mathrm{Pt} / \mathrm{Ir}, \mathrm{Pt} / \mathrm{Rh}, \mathrm{Ag} / \mathrm{Au}, \mathrm{Ag} / \mathrm{Cu}$ ) with a core-shell or alloy structure (Pal et al., 2007; Castillo et al., 2008). Such dynamic colloidal templates are known to produce particles of smaller size than those obtained using normal precipitation in aqueous systems.

\section{Preparation of nanoparticles in microemulsion system}

The preparation procedure of metallic nanoparticles in $\mathrm{W} / \mathrm{O}$ microemulsion commonly consists of mixing of two microemulsions containing metal salt and a reducing agent, respectively as shown in Fig. 1a.

(A)

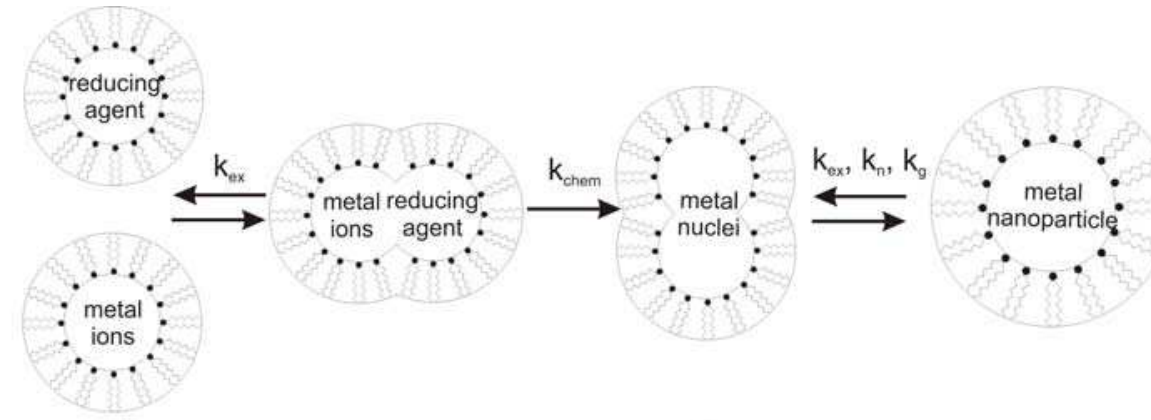

(B)
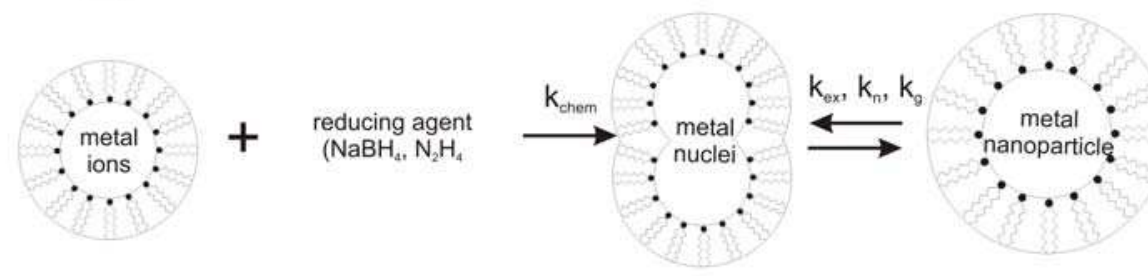

(C)
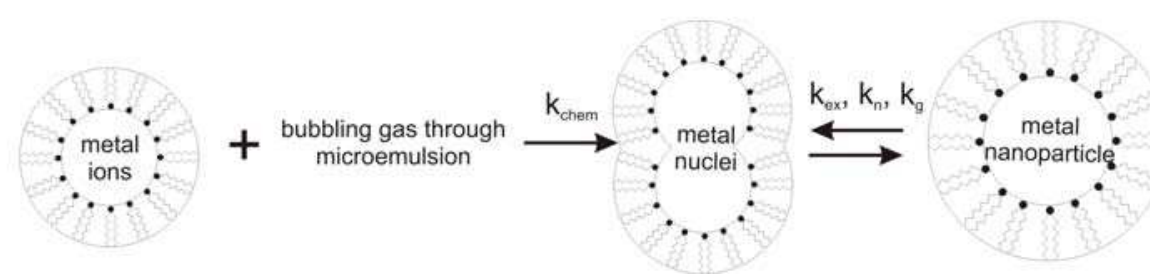

Fig. 1. Schematic illustration of nanoparticles preparation using microemulsion techniques: Particle formation steps. $k_{\text {chem }}$ is the rate constant for chemical reaction, $k_{e x}$ is the rate constant for intermicellar exchange dynamics, $k_{n}$ is the rate constant for nucleation, and $k_{g}$ is the rate constant for particle growth

After mixing two microemulsions, the exchange of reactants between micelles takes place during the collisions of water droplets result of Brownian motion, the attractive van der Waals forces and repulsive osmotic and elastic forces between reverse micelles. Successful collisions lead to coalescence, fusion, and efficient mixing of the reactants. The reaction between solubilizates results in the formation of metal nuclei. Bönnemann et al. reported that at the 
initial stage of the nucleation, metal salt is reduced to give zerovalent metal atoms, which can collide with further metal ions, metal atoms, or clusters to form an irreversible seed of stable metal nuclei (Bönnemann \& Richards, 2001). Growth then occurs around this nucleation point where successful collision occurs between a reverse micelle carrying a nucleus and another one carrying the product monomers with the arrival of more reactants due to intermicellar exchange. The nucleation reaction and particle growth take place within the micelles and the size and morphology of as-prepared nanoparticles depend on the size and shape of the nanodroplets and the type of the surfactant, whose molecules are attached on the surface of the particles to stabilize and protect them against further growth.

Wongwailikhit et al. prepared iron (III) oxide, $\mathrm{Fe}_{2} \mathrm{O}_{3}$ using W/O microemulsion by mixing the required amount of $\mathrm{H}_{2} \mathrm{O}$ in a stock solution of AOT in $n$-heptane. The solution was left overnight, then the concentrated $\mathrm{NH}_{2} \mathrm{OH}$ and $\mathrm{FeCl}_{3}$ were dropped into the W/O microemulsion. Suspension of $\mathrm{Fe}_{2} \mathrm{O}_{3}$ was filtered and washed with $95 \%$ ethanol and dried at $300^{\circ} \mathrm{C}$ for $3 \mathrm{~h}$. They obtained spherical, monodisperse nanoparticles with diameter of about $50 \mathrm{~nm}$. The particles size was depended on the water content in microemulsion system. The increase of particles size was obtained with increasing the water fraction in W/O microemulsion (Wongwailikhit \& Horwongsakul, 2011).

Sarkar et al. prepared pure monodispersed zinc oxide nanoparticles of different shapes. Microemulsion was composed of cyclohexane, Triton X-100 as surfactant, hexanol as cosurfactant and aqueous solution of zinc nitrate or ammonium hydroxide/sodium hydroxide complex. The molar ratio of TX-100 to hexanol was maintained at 1:4. The microemulsion containing ammonium hydroxide/sodium hydroxide was added to microemulsion containing zinc nitrate and stirred. The nanoparticles were then separated by centrifuging at $15,000 \mathrm{rpm}$ for $1 \mathrm{~h}$. The particles were washed with distilled water and alcohol and dried at $50^{\circ} \mathrm{C}$ for $12 \mathrm{~h}$ (Sarkar et al., 2011).

Li et al. prepared nanometer-sized titania particles by chemical reactions between $\mathrm{TiCl}_{4}$ solution and ammonia in microemulsion systems. In order to prepare $\mathrm{W} / \mathrm{O}$ microemulsions, a cyclohexane was used as the oil phase and a mixture of poly (oxyethylene) ${ }_{5}$ nonyle phenol ether (NP5, chemical purity) and poly (oxyethylene) 9 nonyle phenol ether with weight ratio 1:1 as the nonionic surfactant (NP5-NP9). Two microemulsion systems were prepared, containing a $0.5 \mathrm{M}$ titanium tetrachloride $\left(\mathrm{TiCl}_{4}\right)$ aqueous solution and a $2.0 \mathrm{M}$ ammonia as the aqueous phase, respectively. The oil phase, surfactant, and aqueous phase were mixed in an appropriate proportion in a beaker at $13^{\circ} \mathrm{C}$ in a water bath to form the microemulsion. Appropriate amounts of microemulsion I containing $0.5 \mathrm{M} \mathrm{TiCl} 4$ aqueous solution and microemulsion II containing $2.0 \mathrm{M}$ ammonia were mixed together, leading to the formation of insoluble titania particles. The precipitates were centrifuged, washed by the use of acetone, followed by vacuum drying for two hours. $\mathrm{TiO}_{2}$ particles prepared in these systems had average size of about $5 \mathrm{~nm}$ and a narrow size distribution. TEM, DTA-TGA, and Raman spectroscopy studies indicate that their phase transition behavior is close to that of the dry gel prepared by the sol-gel method (Li \& Wang, 1999).

Another method to prepare nanoparticles is from a single microemulsion as shown in Fig. $1 \mathrm{~B}$ and $1 \mathrm{C}$. One of the reactants usually a precursor of metal nanoparticles is solubilised inside reverse micelles and the second reactant (often a reducing agent) added directly to 
the microemulsion system. For the nanoparticles formed in single microemulsions the mechanism is based on intramicellar nucleation and growth and particle aggregation.

This method was applied for the first time by Boutonnet et al. in 1982 for preparation of Pt, $\mathrm{Rh}, \mathrm{Pd}$ and Ir nanoparticles in W/O microemulsion. Metallic nanoparticles were formed in single microemulsions using hexadecyltrimethylammonium bromide (CTAB) or pentaethyleneglycole dodecyl ether (PEGDE) as a stabilizer. The precursors composed of water-soluble metal salts and hydrogen gas, bubbled through the microemulsion, or hydrazine, were added directly to the microemulsion, as the reducing agent (Boutonnet et al., 1982).

Husein et al. described that intramicellar nucleation and growth dominate when high reactant occupancy numbers are coupled with rigid surfactant layer, while intermicellar nucleation and growth dominate at low occupancy numbers and less rigid surfactant layers. At intermediate values of occupancy the number and surfactant layer rigidity, both intramicellar and intermicellar nucleation and growth contribute to the final particle size and polydispersity (Husein \& Nassar, 2008).

Sanchez-Dominguez et al. prepared $\mathrm{Pt}, \mathrm{Pd}$ and $\mathrm{Rh}$ nanoparticles by an oil-in-water microemulsion reaction method. The microemulsion containing metal precursor (Pt-COD, Pd-AAc, Rh-COCl) was prepared by mixing appropriate amounts of surfactant, cosurfactant(s), oil phase and deionized water. The used systems: water/ Tween 80/Span 20/1,2-hexanodiol/ethyl oleate (System A); water/Brij 96V/butyl-S-lactate (System B) and water/Synperonic 10/5/isooctane (System C). Then to the solutions, under vigorous stirring at $25^{\circ} \mathrm{C}$, a small amount of an aqueous solution of sodium borohydride was added (Sanchez-Dominguez et al., 2009).

\section{Effects of the parameters on the formation of nanoparticles in microemulsion}

The formation of nanoparticles in the microemulsion system is a strong function of the intermicellar exchange, which is denoted by the intermicellar exchange rate coefficient $\left(k_{\text {ex }}\right)$ and affected by many factors such as: the type of continuous phase, the precursor content dissolved within the nanodroplets, and the water content, referred to as molar ratio of water to surfactant $(W)$. The high exchange rate between the micelles yields large numbers of nanoparticles with a relatively small diameter. On the contrary, slow exchange of materials between the micelles leads to formation of a few numbers of nuclei and results in larger final particle size.

Bagwe \& Khilar studied the influence of smaller particle size. The micellar exchange rates increase as the chain length of the oil increases from $10^{6} \mathrm{M}^{-1} \mathrm{~S}^{-1}$ for cyclohexane and $10^{7}$ for $n$-heptane to $10^{8} \mathrm{M}^{-1} \mathrm{~s}^{-1}$ for decane. Silver nanoparticles decrease as the chain length of the oil increases from $5.4 \mathrm{~nm}$ for cyclohexane and $6 \mathrm{~nm}$ for decane to $22 \mathrm{~nm}$ for $n$-heptane. Less bulky solvent molecules with lower molecular volumes, such as $n$-heptane or cyclohexane, can penetrate more easily in the surfactant layer, resulting in additional interfacial area and interfacial rigidity. In addition the plasmon absorption peak shifts toward longer wavelengths (red shift) as the particle size increases and the chain length of the oil decreases from decane to $n$-heptane to cyclohexane (Bagwe \& Khilar, 2000). 
Mori et al. reported that the particle size produced in the cyclohexane is slightly smaller than that in the octane system, although the difference in microemulsion sizes is large at the same molar ratio water to surfactant $(W)$. The change in the growth depends on the chain length of the solvent molecules. With increasing of the chain length, the alkane molecules become increasingly coiled and their penetration in the surfactant layer becomes difficult. Thus, the interaction between the surfactant and solvent molecules decreases with an increase in the chain length of the alkane molecules. As a result, the micellar exchange rate increases with the chain length. On the other hand, short chain alkane and cyclohexane molecules can easily penetrate the surfactant layer to generate additional interfacial rigidity. Thus, the micellar exchange rate would decrease, which further affects the formation of silver atoms (Mori et al., 2001).

Petit et al. also reported that larger silver particles were formed in isooctane, bulkier with a larger molecular volume solvent than in cyclohexane (Petit et al., 1993).

The second studied parameter which can influence the nanoparticle size and shape is the type of the surfactants and the addition of the co-surfactants. The surfactants consist of two main entities, a hydrophilic head group and a hydrophobic (or lypophilic) tail group, which form soft aggregates in solvents and are held together by van der Waals and ionic forces. The surfactant acts as a stabilizing agent, effectively dispersing the obtained nanoparticles in the solution, providing sites for the particle nucleation and preventing aggregation of the nanoparticles. In $\mathrm{W} / \mathrm{O}$ microemulsions surfactants form reverse micelles, nano-sized water pools dispersed within the bulk organic solvent which act as nanoreactors for the chemical reduction of the metallic precursors and metallic nanoparticle preparation.

For the most surfactant-mediated synthesis, the connection between morphology of the surfactant aggregates and the resulting particle structure is more complex (than simply relating the average size and shape of the micelles to the size and shape of the precipitated particles). These molecular-level variables are subject to change with macroscopically manipulated experimental conditions, as shown in Table 1.

\begin{tabular}{|c|c|}
\hline Macroscopic parameters & Nano-sized parameters \\
\hline Identity of included chemical species & Static, size and shape of micelles \\
\hline Microemulsion composition & Aggregation number \\
\hline Water-to-surfactant molar ratio & $\begin{array}{l}\text { Dynamic interaction, rates and types of } \\
\text { merging and dissociation of micelles }\end{array}$ \\
\hline & Distribution of charged entities around \\
\hline Ionic strength & dispersed particles \\
\hline Dissolved species concentrations & $\begin{array}{l}\text { Surfactant film curvature and head-group } \\
\text { spacing }\end{array}$ \\
\hline $\begin{array}{l}\text { Method and rate of introduction of species } \\
\text { Temperature and pressure }\end{array}$ & Effective Coulumb repulsion potential \\
\hline Aging time & Van der Waals, hydrogen and \\
\hline Method and rate of stirring & hydrophobic interactions \\
\hline Homogenous or heterogeneous nucleation & Screening length \\
\hline
\end{tabular}

Table 1. Macroscopic and nanoscopic variables in the microemulsion-assisted and particularly reverse-micellar preparation method of nanoparticles (Uskokovic \& Drofenik, 2007) 
Usually, many surfactants can be used to form microemulsion, including cationic surfactants such as cetyltrimethylammonium bromide (CTAB), anionic surfactants such as bis(2ethylhexyl)sulfosuccinate (AOT), sodium dodecyl benzene sulfonate (SDBS) and lauryl sodium sulfate (SDS), and nonionic surfactants such as Triton X-100 and sorbitan monooleate Span 80, nonylphenyl ether (NP-5) or polyoxyethylene (9) nonylphenyl ether (NP-9).

The most commonly used surfactant for the formation of reverse micelles is the sodium bis(2ethylhexyl) sulfosuccinate, also known as Aerosol-OT or AOT, seen in Fig. 2. AOT is a twin tailed, anionic surfactant with a sulfosuccinate head group stabilized as a salt by a sodium cation. The AOT molecule has an inverted conical shaped structure and has proven to be an effective emulsifier, thus finding a wide range of applications as well as numerous intensive studies. The surfactant layer acts as steric stabilizer to inhibit the aggregation of nanoparticles formed. The microemulsion formed by AOT is made up of three kinds of components AOT, water, alkane (without addition of co-surfactants). In this system, micelles consist of a hydrophilic core compartmentalised by the hydrophilic head group of the AOT, forming a "water-pool" characterized by the molar ratio of water to surfactant $\left(W=\left[\mathrm{H}_{2} \mathrm{O}\right] /[\mathrm{AOT}]\right)$ and with the hydrophobic alkyl tails extending into the nonpolar continuous phase solvent.

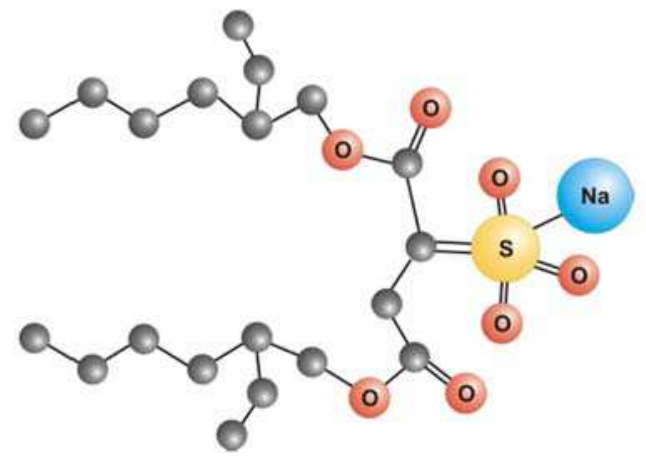

Fig. 2. Model of surfactant molecule bis(2-ethylhexyl)sulfosuccinate (AOT)

AOT microemulsion has extensively been applied for preparation of metallic nanoparticles ( $\mathrm{Pt}$, $\mathrm{Pd}, \mathrm{Cu}, \mathrm{Ag}, \mathrm{Au}, \mathrm{Ni}, \mathrm{Zn})$, metal sulfides (CdS, $\mathrm{ZnS})$ and metal oxides $\left(\mathrm{TiO}_{2}, \mathrm{SiO}_{2}\right)$. The resultant particles have high stability, small particle size, and good monodispersity. Due to its higher solubility in organic phase AOT helps to extract metal cations from the aqueous to reverse micellar phase. In addition the particles formed in AOT microemulsion have relatively strong electrostatic interactions with the negatively charged head polar group of AOT molecules, which comes into being a protective effect against aggregation (Zhang et al., 2007).

In the first papers by Lisiecki \& Pileni on the preparation of metallic nanoparticles, it was demonstrated that both the bulk solvent and $W$ value have an effect on the preparation of copper and silver nanoparticles in the AOT microemulsion system (Lisiecki \& Pileni, 1995).

Table 2 gives a brief summary of various parameters which influence on the size and shape of nanoparticles prepared using the microemulsion method. By going through Table 2, one can observe that AOT has been reported to be the most suitable surfactant for silver nanoparticles preparation, and water-to-surfactant ratio is a crucial parameter in setting up the final size of the obtained nanoparticles. 
Zhang et al. (Zhang et al., 2007; Zhang et al., 2006) reported that silver nanoparticles prepared in AOT microemulsion have a smaller average size and narrower size distribution compared to the particles prepared using cationic or nonionic surfactant in the microemulsion system (Zhang et al., 2007). In addition, due to the adsorption of AOT molecules onto the particles, the resultant sol can be preserved for a long time without precipitation and it easily transfers the obtained nanoparticles into nonpolar solvents (Zhang et al., 2006).

TX-100 (Triton X-100) another commonly used surfactant for preparation of nanoparticles in $\mathrm{W} / \mathrm{O}$ microemulsion has extensively been applied for preparation of monodisperse gold, nickel, copper, and semiconductors nanoparticles such as titanium dioxide and silica but as performed reseraches have shown this surfactant is not sufficient for stabilization of silver nanoparticles in the microemulsion system. This nonionic surfactant reveals strong solvent dependence for the formation of reverse micelles. Because of the presence of long polyoxyethylene group the polar interior of the reverse micellar aggregate would be of different nature; it is also expected that the TX-100 system would show a different phase behavior compared to AOT molecules.

Spirin et al. compared stability of the gold colloids prepared in W/O microemulsion system. They found that gold nanoparticles formed in water/Triton X-100/hexane microemulsions were much smaller than those obtained in AOT-based microemulsion system. It was suggested, that for nonionic surfactant TX-100 gold nanoparticles were formed in the micelle shell rather than in the water pool. In the shell, the gold clusters were stabilized by oxyethylene groups of TX-100 molecules. In addition 0.1 M 1-hexanol used as a co-surfactant in water/TX-100/cyclohexane system, could decrease the particle size (Spirin et al., 2005). For gold nanoparticles obtained in reverse micelles of the water/AOT/cyclohexane system, particles could grow through intermicellar exchange followed by agglomeration. The exchange rate for AOT-based microemulsion is higher than for nonionic TX-100-based microemulsion. Therefore, the collision probability between particles in AOT-stabilized microemulsion can be higher, and as a consequence, gold particles can agglomerate easier than in nonionic TX-100 microemulsion.

Hong et al. investigated the effect of concentration of surfactants and the hydrophilic group chain length of surfactant on the physical properties of nanosized $\mathrm{TiO}_{2}$ particles. Non-ionic surfactants - Brij 52 (polyoxyethylene glycol hexadecyl ether polyethylene 2-cetyl ether), Brij 56 (polyoxyethylene glycol hexadecyl ether polyethylene 10-cetyl ether), Brij 58 (polyoxyethylene glycol hexadecyl ether polyethylene 20 cetyl ether) were employed in this work. For the Brij series, head group size increases from Brij 52 to Brij 58 (average number of oxyethylene groups increases from 2 to 20), but with a constant tail length (average number of hydrophobic carbons is 16). They have found that the photocatalytic activity and also the size of the particles increased with an increase of hydrophilic group chain length (Hong et al., 2003).

Solanki et al. studied the effects of reaction parameters, including water-to-surfactant ratio (W), type of continuous oil phase in water/AOT/cyclohexane microemulsion system. They found that silver nanoparticles were smaller and narrower in the size distribution at lower water content than that obtained at higher $W$ value. When $W$ values increased from 5 to 8 the particle size increased from 4-9 $\mathrm{nm}$ to 50-58 nm (Solanki et al., 2010).

Chen et al. prepared platinum ultrafine particles by the reduction of $\mathrm{H}_{2} \mathrm{PtCl}_{6}$ with hydrazine in AOT/isooctane microemulsion system. They have found that the hydrodynamic 
diameters of reverse micelles measured by DLS increased with the increase of $\mathrm{W}$ values. When the aqueous phase was the solution of $0.1 \mathrm{M} \mathrm{H}_{2} \mathrm{PtCl}_{6}$ or $1.0 \mathrm{M}$ hydrazine, it was observed that the reverse micellar sizes were smaller than those obtained using water as the aqueous. It could be attributed to the fact that the dissociation of $\mathrm{H}_{2} \mathrm{PtCl}_{6}$ or hydrazine in solution caused the increase of ionic strength, which reduced the repulsion between the head groups of ionic surfactant and led to the formation of smaller reverse micelles (Chen et al., 1999). The formation rate was faster at larger $W$ values. This could be attributed to the fact that the number of nuclei formed in aqueous phase increased as the $\mathrm{W}$ value increased at constant $\mathrm{AOT}$ and $\mathrm{H}_{2} \mathrm{PtCl}_{6}$ concentrations, leading to the increase in the formation rate.

Inaba et al. prepared titanium dioxide nanoparticles in microemulsion system composed of water, Triton X-100 and isooctane. The $\mathrm{TiO}_{2}$ nanoparticles showed monodispersity, a large surface area and high degrees of crystallinity and thermostability. The particle size of $\mathrm{TiO}_{2}$ was controlled by changing the water content of the reverse micellar solution (Inaba et al., 2006).

We have earlier investigated the effect of various surfactants on silver and gold nanoparticle size deposited on $\mathrm{TiO}_{2}$ surface using the microemulsion system. We have found that the primary gold particles size was dependent on the type of the surfactant (anionic AOT, nonionic TX100 or nonionic Span 80) and reducing agent $\left(\mathrm{N}_{2} \mathrm{H}_{4}, \mathrm{NaBH}_{4}\right)$, which was used for stabilization and reduction of gold ions in the microemulsion system. For nonionic surfactant Triton X-100 or Span 80 smaller gold nanoparticles with the diameter of about $20 \mathrm{~nm}$ were obtained. Our results proved that the size of gold is the key-factor for high level activity under visible-light irradiation. When anionic AOT (sodium bis-2-ethylhexylsulfosuccinate) was used, the size of gold nanoparticles averaged $70 \mathrm{~nm}$ and it was beneficial related to higher photocatalytic activity observed for larger gold nanoparticles deposited on titania surface. We have also found that the decrease of water to surfactant molar ratio $(W)$ from 6 to 3 during preparation in water/AOT/cyclohexane system resulted in the decrease in gold particle size from 68 to $38 \mathrm{~nm}$. The decrease in $W$ value favored the formation of smaller water droplets and led to the decrease in the average gold particles size. Titania size added during precipitation of noble metal nanoparticles can also slightly influence the size of gold in the microemulsion method. Due to the presence of hydroxyl groups on the $\mathrm{TiO}_{2}$ surface, $\mathrm{TiO}_{2}$ possesses highly hydrophilic properties which influence micelles water pools properties. The smaller titania particles were used, the smaller metal particles were obtained in $\mathrm{W} / \mathrm{O}$ microemulsion system. It is expected that smaller particles with higher specific surface area exert more influence on the surface tension of micelle shell than larger $\mathrm{TiO}_{2}$ nanoparticles. We have also found that gold particles obtained in the air atmosphere were large and polydisperse due to oxidized for $\left[\mathrm{Au}(\mathrm{OH})_{4}\right]^{-}$formation. Therefore, the obtained $\mathrm{Au}-\mathrm{TiO}_{2}$ photocatalysts prepared in the air atmosphere revealed lower photocatalytic activity in visible region compared to the samples obtained in argon or nitrogen atmosphere (Zielińska-Jurek et al., 2011).

Ganguli et al. discussed the effect of various surfactants on the morphology of nanomaterials. They reported that cationic surfactants lead to anisotropy and preparation of nanorods of several divalent metal carboxylates. They explained that an isotropic growth occurs when using the non-ionic surfactant TX-100 leading to spherical nanoparticles of $(\sim 5 \mathrm{~nm})$. On changing the non-ionic surfactant from TX-100 to Tergitol, larger cubes of size of about $50 \mathrm{~nm}$ were formed. They explained that the positively charged surfactants assemble on the surface of the negatively charged nickel oxalate and thus favor the 
anisotropic growth (rods). In the absence of such positively charged surfactants, an isotropic growth leads to spheres and nanocubes. Thus the choice of the surfactant becomes critical to the size, shape and stability of the nanoparticles obtained in microemulsion (Ganguli et al., 2010). In a mixed cationic-anionic surfactant solution, such as the synergism, the formation of a worm-like micelle is favored, which directs the growth of the one-dimensional nanostructure (Petit et al., 1993).

Another important factor which determines size and shape of nanoparticles is the addition of electrolytes. Generally addition of salt influences the degree of dissociation of emulsifier, the solubility of emulsifier in the aqueous phase and the micelle aggregation number. In the interesting review on preparation of silver nanoparticles Zhang et al. summarized that the presence of electrolyte is favorable for the formation of silver nanowires (Zhang et al., 2007).

Chiang et al. reported that addition of $2.5 \mathrm{M}$ of $\mathrm{NaCl}$ in the water pool of reverse micelles in water-AOT-isooctane microemulsion induces a marked change in the particle shape with appearance of cylinders, trigons and cubics (Chiang et al., 2004). They have also found that the control of the final Au nanoparticle size and shape was related to the molar ratio of the reduction agent to the precursor and the sequence of the addition of metal salt into the mixed reverse micelles. A decrease in the molar ratio of the reduction agent to the precursor and direct injection of precursor to mixed reverse micelles containing the reduction agent resulted in the formation of anisotropic gold nanoparticles, such as cylinders and trigons (Chiang et al., 2004).

Jang et al. reported that the diameter of polypyrrole nanotubes were affected by different microemulsion parameters such as, the weight ratio of aqueous $\mathrm{FeCl}_{3}$ solution/AOT, type of nonpolar solvent, and reaction temperature. Polypyrrole nanotubes were formed through chemical oxidation polymerization in microemulsion consist of $74.0 \mathrm{wt} \%$ of hexane, $22.4 \mathrm{wt}$ $\%$ of $\mathrm{AOT}$ and $3.6 \mathrm{wt} \%$ of aqueous $\mathrm{FeCl}_{3}$ solution at $15^{\circ} \mathrm{C}$, as shown in Fig. 3. It was found that an aqueous $\mathrm{FeCl}_{3}$ solution determines the formation of rod-shaped AOT micelles by decreasing the second critical micelle concentration responsible for structural transitions of spherical micelles and increasing the ionic strength of the solvent. The average diameter of polypyrrole nanotubes was approximately $94 \mathrm{~nm}$ and their length was more than $2 \mu \mathrm{m}$ (Jang \& Yoon, 2005).

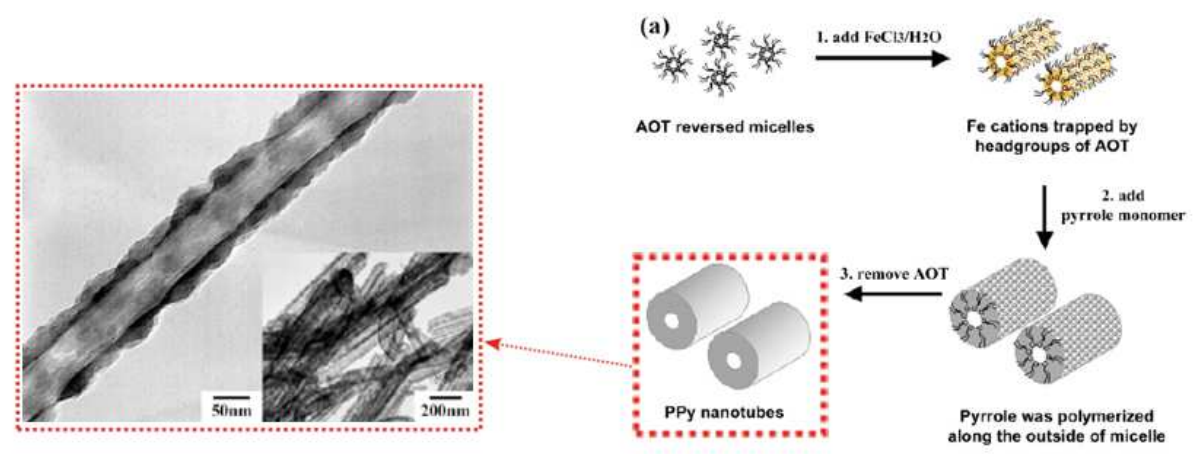

Fig. 3. TEM image and schematic route for the preparation of polypyrrole nanotubes in W/O microemulsion (Jang \& Yoon, 2003) 


\begin{tabular}{|c|c|c|c|c|c|c|}
\hline $\begin{array}{l}\text { Metal/ } \\
\text { Metal } \\
\text { oxides }\end{array}$ & $\begin{array}{c}\text { Microemulsion } \\
\text { system } \\
\text { (surfactant } \\
\text { /co- } \\
\text { surfactant/oil) }\end{array}$ & Precursor & $\begin{array}{c}\text { Reducing } \\
\text { Agent }\end{array}$ & $\begin{array}{c}\text { Particle } \\
\text { diameter and } \\
\text { shape }\end{array}$ & $\begin{array}{c}\text { Parameters } \\
\text { determining the size } \\
\text { and shape of } \\
\text { nanoparticles }\end{array}$ & 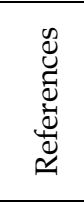 \\
\hline $\mathrm{Ag}$ & $\begin{array}{l}\text { Brij 30/AOT/ } \\
n \text {-heptane }\end{array}$ & $\mathrm{AgNO}_{3}$ & Brij 30 & $\begin{array}{l}\text { 3-6 nm and } \\
20-30 \mathrm{~nm} \\
\text { spherical } \\
\text { nanoparti- } \\
\text { cles }\end{array}$ & $\begin{array}{l}\text { Weight ratios } \\
{[\text { Brij30]/([AOT] }+[\text { Brij3 }} \\
0])=1,0.75,0.5,0.25,0 \\
\text { Aqueous solution } \\
\text { contained } 1,2, \\
\text { or } 3 \text { wt } \% \mathrm{AgNO}_{3}\end{array}$ & 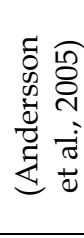 \\
\hline $\mathrm{Ag}$ & $\begin{array}{l}\text { AOT/ } \\
\text { cyclohexane } \\
\text { AOT/ } \\
\text { isooctane }\end{array}$ & $\mathrm{AgNO}_{3}$ & $\mathrm{NaBH}_{4}$ & 5-55 nm & $\begin{array}{l}\text { Water to surfactant } \\
\text { molar ratio } \\
W=5 \text { or } 8 \\
\text { Molar ratio of reducing } \\
\text { agent to reagent } \\
(\mathrm{R}=0.66-1.5)\end{array}$ & 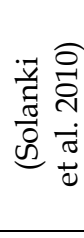 \\
\hline $\mathrm{Ag}$ & $\begin{array}{l}\text { SDS/isoamyl } \\
\text { alcohol/ } \\
\text { cyclohexane }\end{array}$ & $\mathrm{AgNO}_{3}$ & $\mathrm{NH}_{2} \mathrm{OH}$ & $\begin{array}{l}6.5 \mathrm{~nm} \\
\text { spherical } \\
\text { nanoparti- } \\
\text { cles }\end{array}$ & $\begin{array}{l}\text { Molar ratio of } \\
\mathrm{N}_{2} \mathrm{H}_{4} / \mathrm{Ag}^{+}=3 / 1 \\
\text { Molar ratio of } \\
\mathrm{W}=\mathrm{H}_{2} \mathrm{O} / \mathrm{SDS}=5\end{array}$ & 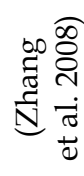 \\
\hline $\begin{array}{l}\mathrm{Pt}, \mathrm{Pd}, \\
\mathrm{Rh}\end{array}$ & $\begin{array}{l}\text { Tween 80, } \\
\text { Span 20/1,2- } \\
\text { hexanodiol/ } \\
\text { ethyl olate } \\
\text { Brij 96V/ } \\
\text { butyl-S-Lactate } \\
\text { Synperonic- } \\
\text { 10/isooctane }\end{array}$ & $\begin{array}{l}\text { Pt-COD, } \\
\text { Pd-AAc, } \\
\text { Rh-COCl }\end{array}$ & $\mathrm{NaBH}_{4}$ & $\begin{array}{l}3.1-6.3 \mathrm{~nm} \\
\text { undefined } \\
\text { shape }\end{array}$ & $\begin{array}{l}\text { molar ratio of } \\
\mathrm{NaBH}_{4} / \text { metal }=2 / 1 \\
\text { Oil phase content } \\
(5-20 \% \text { wt. }) \\
\text { Surfactant content } \\
(9-25 \% \text { wt. }) \\
\text { Water content } \\
(60-83,5 \% \text { wt. }) \\
\text { Metal content } \\
(0.08-2.58 \text { [g/kg of } \\
\text { microemulsion] })\end{array}$ & 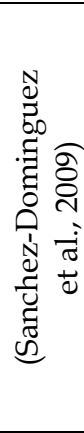 \\
\hline
\end{tabular}

Table 2. Survey of recent publications on metal/metal oxide particles prepared using microemulsion method.

\section{Bimetallic, core-shell nanoparticles and alloys}

Bimetallic composite nanoparticles, composed of two different metal elements, are of greater interest than monometallic nanoparticles from both scientific and technological point of view. The structure of bimetallic nanoparticles is defined by the distribution modes of the two elements and can be oriented in random alloy, alloy with an intermetallic compound, cluster-in-cluster and core-shell structures. The bimetallic nanoparticles have unique catalytic, electronic, and optical properties distinct from those of the corresponding metallic particles. The structure of bimetallic combinations depends on the preparation conditions, miscibility, and kinetics of the reduction of metal ions. 
Silver and gold have almost identical lattice constants (0.408 for Au and 0.409 for $\mathrm{Ag}$ ) and are completely miscible over the entire composition range, which leads to a strong tendency toward alloy formation. Hence single-phase alloys can be achieved with any desired composition and the absorption spectra of alloy nanoparticles exhibit only one surface plasmon band, whose absorption maximum depends on the alloy composition. The optical properties of metal nanoparticles depend on surface plasmon resonance. The origin of surface plasmon resonance in noble metal nanoparticles is the free conduction electrons in the metal surface ( $d$ electrons in silver and gold). The mean free path of the electrons in the gold and silver is $50 \mathrm{~nm}$. Therefore, for the particles smaller than $50 \mathrm{~nm}$, no scattering is expected from the bulk. Hence all the spectral properties are the function of the surface and not of bulk. According to Mie theory the total extinction coefficient of small metallic particles is the summation of all electronic and magnetic multipole oscillations, contributing to the absorption and scattering of the interacting electromagnetic field. Now for the particles much smaller than the wavelength of the absorbing light only the dipole term is assumed to contribute to the absorption. The electric field of the incoming electromagnetic radiation induces the formation of a dipole in the nanoparticles. A restoring force in the nanoparticles tries to compensate for this, resulting in a unique resonance wavelength. Alloy nanoparticles have received a special attention due to the possibility of tuning their optical and electronic properties over a broad range by simply varying the alloy composition. The characteristics of the bimetallic nanoparticles are listed in Table 3.

Xia et al. obtained well-dispersed Ag/Ni core-shell nanoparticles using reduction of silver nitrate and nickel nitrate with sodium borohydride in water-in-oil $(\mathrm{W} / \mathrm{O})$ microemulsions of water/polyoxyethylene (4) nonylphenol (OP-4) and polyoxyethylene (7) nonylphenol (OP7)/n-heptane. To prepare $\mathrm{Ag} / \mathrm{Ni}$ nanoparticles the required amount of sodium hydroxide aqueous solution was added to the mixture of nickel nitrate and silver nitrate (in a molar ratio of 2:1) aqueous solutions to form fine precipitates of $\mathrm{Ag}_{2} \mathrm{O}$ and $\mathrm{Ni}(\mathrm{OH})_{2}$. Ammonia solution was added drop by drop to this mixture until the precipitates completely dissolved to form $\left[\mathrm{Ag}\left(\mathrm{NH}_{3}\right)_{2}\right]^{+}$and $\left[\mathrm{Ni}\left(\mathrm{NH}_{3}\right)_{6}\right]^{2+}$, then pure water was added. Next, under continuous mechanical stirring, OP-4, $n$-heptane, OP-7 was added, into the above $\left[\mathrm{Ag}\left(\mathrm{NH}_{3}\right)_{2}\right]^{+}$and $\left[\mathrm{Ni}\left(\mathrm{NH}_{3}\right)_{6}\right]^{2+}$ solution, and remained for $30 \mathrm{~min}$ in water-bath at $25^{\circ} \mathrm{C}$. The second microemulsion was prepared in a similar way, except that metal precursor was replaced by sodium borohydride aqueous solution. The first microemulsion was added dropwise into the second one, and left for $1 \mathrm{~h}$ in water-bath at $25^{\circ} \mathrm{C}$ under continuous mechanical stirring. The products were washed several times with water and anhydrous ethanol, and then dried under vacuum at room temperature for $4 \mathrm{~h}$ (Xia et al., 2010).

Ahmed et al. obtained bimetallic $\mathrm{Cu} / \mathrm{Ni}$ nanoparticles using $\mathrm{CTAB}$ (cetyltrimethyl ammoniumbromide) as the surfactant, 1-butanol as the co-surfactant and isooctane as the oil phase and hydrazine/ $\mathrm{NaOH}$ as the precipitating agents followed by the reduction in hydrogen atmosphere. They prepared four microemulsions with different aqueous phases containing $\mathrm{Cu}\left(\mathrm{NO}_{3}\right)_{2} \cdot 3 \mathrm{H}_{2} \mathrm{O}, \mathrm{Ni}\left(\mathrm{NO}_{3}\right)_{2} \cdot 6 \mathrm{H}_{2} \mathrm{O}, \mathrm{N}_{2} \mathrm{H}_{4} \cdot \mathrm{H}_{2} \mathrm{O}$ and $\mathrm{NaOH}$. Microemulsions A and $\mathrm{B}$ were created by mixing two solutions, $\mathrm{A}$ - containing metal precursors, $\mathrm{B}$ - reducing agents. The obtained green precipitate was washed with 1:1 chloroform/methanol mixture and dried in the air, then heated to $500^{\circ} \mathrm{C}$ for $5 \mathrm{~h}$. (CuNi). They had also prepared $\mathrm{CuNi}_{3}$ and $\mathrm{Cu}_{3} \mathrm{Ni}$ nanoparticles using the same method (Ahmed et al., 2008). 


\begin{tabular}{|c|c|c|c|c|}
\hline $\begin{array}{c}\text { Chemical } \\
\text { composition } \\
\text { of nanoparticles }\end{array}$ & Preparation method & Precursor & $\begin{array}{c}\text { Reducing } \\
\text { agent }\end{array}$ & Particle diameter and shape \\
\hline $\begin{array}{l}\mathrm{Ag} / \mathrm{Ni} \\
\text { nanoparticles }\end{array}$ & $\begin{array}{l}\text { To prepare } \mathrm{Ag} / \mathrm{Ni} \text { nanoparticles the required } \\
\text { amount of sodium hydroxide aqueous solution was } \\
\text { added to the mixture of nickel nitrate and silver } \\
\text { nitrate (in a molar ratio of } 2: 1) \text { aqueous solutions to } \\
\text { form fine precipitates of } \mathrm{Ag}_{2} \mathrm{O} \text { and } \mathrm{Ni}(\mathrm{OH})_{2} \text {. } \\
\text { Ammonia solution was added drop by drop to this } \\
\text { mixture until the precipitates completely dissolved } \\
\text { to form }\left[\mathrm{Ag}\left(\mathrm{NH}_{3}\right)_{2}\right]^{+} \text {and }\left[\mathrm{Ni}\left(\mathrm{NH}_{3}\right)_{6}\right]^{2+} \text {, then pure } \\
\text { water was added. } \mathrm{Ag} / \mathrm{Ni} \text { bimetallic nanoparticles } \\
\text { were prepared by dropwise addition } \\
\text { microemulsion containing metal precursors in } \\
\text { water cores into the microemulsion containing the } \\
\text { reducing agent }\left(\mathrm{NaBH}_{4}\right)\end{array}$ & $\begin{array}{c}\mathrm{AgNO}_{3} \\
\mathrm{Ni}\left(\mathrm{NO}_{3}\right)_{2}\end{array}$ & $\mathrm{NaBH}_{4}$ & $\begin{array}{l}50-100 \mathrm{~nm} \text { core-shell structure } \\
\text { and spherical shape } \\
\text { The gold shells formed on thes } \\
\mathrm{Ni} \text { cores were driven by the } \\
\text { spontaneous reaction between } \\
\mathrm{Ni} \text { atoms on the surface of the } \\
\text { nanoparticles and subsequently } \\
\text { added } \mathrm{Au}^{3+} \text { ions }\end{array}$ \\
\hline $\begin{array}{l}\mathrm{Ag} / \mathrm{Au} \\
\text { nanoparticles }\end{array}$ & $\begin{array}{l}\mathrm{Ag} / \mathrm{Au} \text { nanoparticles were prepared by the } \\
\text { microemulsion method using Triton X-100 as a } \\
\text { surfactant, cyclohexane as oil phase and 1-hexanol } \\
\text { as a co-surfactant. Reverse micelle systems } \\
\text { containing a reducing agent and a metal compound } \\
\text { solution were mixed under stirring }\end{array}$ & $\begin{array}{l}\mathrm{AgNO}_{3} \\
\mathrm{HAuCl}_{4}\end{array}$ & $\mathrm{NaBH}_{4}$ & $\begin{array}{l}\text { 20-30 } \mathrm{nm} \\
\text { undefined shape }\end{array}$ \\
\hline $\begin{array}{l}\mathrm{Ni} / \mathrm{Au} \\
\text { nanoparticles }\end{array}$ & $\begin{array}{l}\mathrm{NiCl}_{2} \text { aqueous solution to Brij30 and n-octane } \\
\text { solution. The second microemulsion containing } \\
\mathrm{NaBH}_{4} \text { with the proportions identical to those in } \\
\text { the first one was then added dropwise. The } \\
\text { reaction was pertained under argon atmosphere. } \\
\text { The gold shells formed on these Ni cores were } \\
\text { driven by the spontaneous reaction between the Ni } \\
\text { atoms on the surface of the Ni nanoparticles and } \\
\text { subsequently added } \mathrm{Au}^{3+} \text { ions. The reverse } \\
\text { microemulsion solution containing } \mathrm{HAuCl} \\
\text { added was by drop to the earlier prepared } \\
\text { microemulsion containing } \mathrm{Ni}^{2+}\end{array}$ & $\begin{array}{l}\mathrm{NiCl}_{2} \\
\mathrm{AuCl}_{4}\end{array}$ & $\mathrm{NaBH}_{4}$ & $8 \mathrm{~nm}$ core-shell structure \\
\hline
\end{tabular}




\begin{tabular}{|c|c|c|c|c|}
\hline $\begin{array}{c}\text { Chemical } \\
\text { composition } \\
\text { of nanoparticles }\end{array}$ & Preparation method & Precursor & $\begin{array}{l}\text { Reducing } \\
\text { agent }\end{array}$ & Particle diameter and shape \\
\hline $\begin{array}{l}\text { Ag/ Au core- } \\
\text { shell bimetallic } \\
\text { clusters }\end{array}$ & $\begin{array}{l}0.8 \mathrm{~mL}^{-} \mathrm{NaBH}_{4} \text { and } 5 \mathrm{~mL} \text { of citric acid was added } \\
\text { to } \mathrm{AgNO}_{3} \text { solution. A solution of } 0.4 \mathrm{mM} \mathrm{Ag}^{+} \text {and } \\
0.1-0.4 \mathrm{mM} \mathrm{AuCl}_{4}-\text { was prepared by dissolving the } \\
\text { corresponding salt in water. The reaction mixture } \\
\text { was stirred for } 15 \mathrm{~min} \text { at } 100 \times \mathrm{C} \text {, then gold metal salt } \\
\text { solution was added to the solution of Ag } \\
\text { nanoparticles. Eventually, heating was stopped and } \\
\text { stirring continued for } 10 \mathrm{~min}\end{array}$ & $\begin{array}{l}\mathrm{AgNO}_{3} \\
\mathrm{HAuCl}_{4}\end{array}$ & $\mathrm{NaBH}_{4}$ & $\begin{array}{l}\text { 3-4 nm core-shell bimetallic } \\
\text { clusters } \\
\text { the absorption spectra of } \\
\text { bimetallic nanoparticles } \\
\text { suggested the formation of } \\
\text { core-shell structure }\end{array}$ \\
\hline $\begin{array}{l}\mathrm{Ag} / \mathrm{Au} \text { alloy } \\
\text { nanoparticles }\end{array}$ & $\begin{array}{l}\text { Ag-Au alloy nanoparticles were obtained by } \\
\text { reduction } \mathrm{HAuCl}_{4} \text { and } \mathrm{AgNO}_{3} \text { with } \mathrm{NaBH}_{4} \text { in the } \\
\text { presence of sodium citrate at room temperature. } \\
\text { Five } 125 \mathrm{~mL} \text { flasks were filled with } 100 \mathrm{ml} \text { of } \\
\text { deionized water and } 50 \mathrm{ml} \text { of } 0.01 \mathrm{M} \text { sodium citrate. } \\
\text { Varying mole fractions of } 26 \mathrm{mM} \mathrm{HAuCl}_{4} \text { and } \\
58 \mathrm{mM} \mathrm{AgNO} \mathrm{H}_{3} \text { were added to each solution for a } \\
\text { total metal salt concentration of } 0.005 \mathrm{mM} \text {. }\end{array}$ & $\begin{array}{l}\mathrm{AgNO}_{3} \\
\mathrm{HAuCl}_{4}\end{array}$ & $\mathrm{NaBH}_{4}$ & $\begin{array}{l}10 \mathrm{~nm} \text { Ag-Au alloy nanopartic } \\
\text { optical absorption spectra reve } \\
\text { that the nanoparticles have bee } \\
\text { prepared for alloy structure } \\
\text { nanoparticles }\end{array}$ \\
\hline $\begin{array}{l}\mathrm{Ag} / \mathrm{Au} \\
\text { nanoparticles }\end{array}$ & $\begin{array}{l}\text { W/O microemulsion solutions hydrazine/ } \\
\mathrm{HAuCl}_{4} / \mathrm{AgNO}_{3} \\
\text { Solutions containing } \mathrm{HAuCl}_{4} \text { and } \mathrm{AgNO}_{3} \text { were } \\
\text { obtained by mixing the } \mathrm{W} / \mathrm{O} \text { microemulsion } \\
\text { solution containing } \mathrm{HAuCl}_{4} \text { and that containing } \\
\mathrm{AgNO}_{3} \text {. The preparation of bimetallic nanoparticles } \\
\text { was achieved by mixing equal volumes of two } \mathrm{W} / \mathrm{O} \\
\text { microemulsion solutions at the same molar ratio of } \\
\text { water to Aerosol OT }\left(\mathrm{v}_{0}\right) \text { and concentration of } \\
\text { Aerosol OT, one containing an aqueous solution of } \\
\text { metal salts and the other containing an aqueous } \\
\text { solution of hydrazine }\end{array}$ & $\begin{array}{l}\mathrm{HAuCl}_{4} \\
\mathrm{AgNO}_{3}\end{array}$ & hydrazine & $\begin{array}{l}\text { particle size analysis indicated } \\
\text { that the resultant bimetallic } \\
\text { nanoparticles were } \\
\text { monodisperse and had a mean } \\
\text { diameter of } 4-22 \mathrm{~nm} \text {, } \\
\text { increasing with an increase in } \\
\text { the } \mathrm{W}=\left(\left[\mathrm{H}_{2} \mathrm{O}\right] /[\mathrm{AOT}]\right) \text { value } \\
\text { and } \mathrm{Ag} \text { content }\end{array}$ \\
\hline
\end{tabular}



\begin{tabular}{|c|l|l|l|l|}
\hline $\begin{array}{c}\text { Chemical } \\
\text { composition }\end{array}$ & Preparation method & Precursor & $\begin{array}{c}\text { Reducing } \\
\text { agent }\end{array}$ & Particle diameter and sha
\end{tabular} of nanoparticles agent

?ִ

\begin{tabular}{|l|l|}
\hline & For the preparation of $\mathrm{Ag}-\mathrm{Au}$ alloy nanoparticles \\
\hline
\end{tabular} $\mathrm{AgNO}_{3}$ solution $(0.01 \mathrm{M}), \mathrm{HAuCl}_{4}$ solution $(0.01 \mathrm{M})$ polyacrylamide solution equal volumes of $\mathrm{AgNO}_{3}$, nanoparticles $\mathrm{HAuCl}_{4}$, hydrazine hydrate and tri-sodium citrate ( $3 \%$ of polyacrylamide volume) were added and the reaction was carried out under microwave for

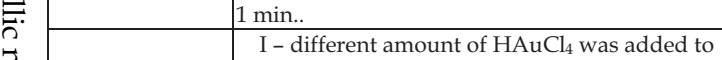
water, $5 \mu \mathrm{l}$ of $0.1 \mathrm{M} \mathrm{CTAB}$ was added to each solution. After that, different amount of $0.1 \mathrm{M}$ ascorbic acid were added to solutions. At last, $500 \mu \mathrm{l}$ of $\mathrm{Ag}$ colloids was added to the three solutions.

II $-10 \mu \mathrm{l}$ of $6 \mathrm{mM} \mathrm{HAuCl}_{4}$ and $5 \mu \mathrm{l}$ of $0.1 \mathrm{M}$ $\mathrm{CTAB}$ were added to water, and the three solutions called D, E and F. $3 \mu \mathrm{l}$ of $0.1 \mathrm{M}$ ascorbic acid was added to each solution. Ag colloids were added to the solutions D, E and F.

$\mathrm{HAuCl}_{4}$ $\mathrm{AgNO}_{3}$ hydrazine methods are in the range $c$ $50 \mathrm{~nm}$

change in the colour of $\mathrm{tl}$ solution indicates the form of alloy nanoparticles wi different composition

$\operatorname{Ag}(\mathrm{Au})$

bimetallic coreshell nanoparticles
20-50 nm

$\mathrm{Ag}(\mathrm{Au})$ bimetallic core-sl nanoparticles

$\mathrm{HAuCl}_{4}$ ascorbic acid the amount of $\mathrm{AuCl}_{4}$ - had effect on the shape of nanoparticles 
Based on the use of $\mathrm{W} / \mathrm{O}$ microemulsions we have proposed a novel method for preparation of the photocatalysts obtained by gold nanoparticles deposition or gold and silver (bimetallic nanocomposites) deposition on the $\mathrm{TiO}_{2}$ surface.

$\mathrm{Ag} / \mathrm{Au}$-modified titanium dioxide nanoparticles were prepared by adding silver precursor into water/AOT/cyclohexane microemulsion containing gold precursor in water cores. The water content was controlled by fixing the molar ratio of water to the surfactant $(W)$ at 4 . Stirring was carried out for $1 \mathrm{~h}$ under argon and then gold and silver ions were reduced by dropwise addition of microemulsion containing a reducing agent. The addition of $\mathrm{NaBH}_{4}$ or $\mathrm{N}_{2} \mathrm{H}_{4}$ to $\mathrm{HAuCl}_{4}$ solution, changed the color from yellow to pinkish red for smaller nanoparticles with the diameter of about $10 \mathrm{~nm}$ and grey for larger nanoparticles with the diameter of about $100 \mathrm{~nm}$, respectively. Finally, $\mathrm{Ag} / \mathrm{Au}-\mathrm{TiO}_{2}$ nanoparticles were prepared by adding $\mathrm{TiO}_{2}$ precursor titanium tetraisopropoxide (TIP) or powdered into the microemulsion containing gold nanoparticles in water cores. Precipitated $\mathrm{Ag} / \mathrm{Au} / \mathrm{TiO}_{2}$ nanoparticles were centrifuged ( $2000 \mathrm{rpm}$ for $5 \mathrm{~min}$ ), washed with ethanol, acetone and water to remove the remaining surfactant, dried at $80^{\circ} \mathrm{C}$ for $48 \mathrm{~h}$ and calcinated at $450^{\circ} \mathrm{C}$ for $2 \mathrm{~h}$.

We have found that bimetallic nanoparticles deposited on titania surface enhanced their photocatalytic activity in visible region. The photodegradation rate of model organic pollutant ( $0.21 \mathrm{mM}$ phenol aqueous solution) under visible light equaled to 0.46 and $1.30 \mu \mathrm{mol} \mathrm{\textrm {dm } ^ { - 3 }}$ $\mathrm{min}^{-1}$ for $\mathrm{TiO}_{2}$ nanoparticles modified by $1.5 \mathrm{~mol} \%$ of $\mathrm{Au}$ or $4.5 \mathrm{~mol} \%$ of $\mathrm{Ag}$ introduced into microemulsion system, respectively. The introduction of the same amount of both silver and gold precursor resulted in the increase of phenol degradation rate up to $3.57 \mu \mathrm{mol} \mathrm{dm}^{-3} \mathrm{~min}^{-1}$. Higher silver amount was more beneficial to the photocatalytic activity of the obtained $\mathrm{Ag} / \mathrm{Au}-\mathrm{TiO}_{2}$ nanoparticles than higher gold amount (Zielińska-Jurek, 2011).

In order to obtain $\mathrm{Ag} / \mathrm{Cu}-\mathrm{TiO}_{2}$ nanoparticles two microemulsions were prepared by mixing the aqueous solution of metal ions $\left(\mathrm{Ag}^{+}, \mathrm{Cu}^{2+}\right.$ ) and $\mathrm{N}_{2} \mathrm{H}_{4} \cdot \mathrm{H}_{2} \mathrm{O}$ into the $0.2 \mathrm{M}$ AOT/cyclohexane solution (Zielińska-Jurek, 2010). Cu or Ag/Cu bimetallic nanoparticles were prepared by dropwise addition microemulsion containing the reducing agent (hydrazine) into the microemulsion containing metal precursor in water cores as was shown in Fig. 4. The molar ratio of hydrazine and silver nitrate or copper nitrate was held constant at the value of 3 . Water content was controlled by fixing the molar ratio of water to surfactant $(W)$ at 2 . Then $\mathrm{TiO}_{2}$ precursor titanium tetraisopropoxide $(0.2 \mathrm{M}$ TIP) was added into the microemulsion containing metal nanoparticles. The concentration of metal precursors, which varied from 0.1 to $6.5 \mathrm{~mol} \%$, was related to the concentration of TIP in the microemulsion system. During the precipitation nitrogen was bubbled continuously through the solution.

The $\mathrm{Ag} / \mathrm{Cu}-\mathrm{TiO}_{2}$ precipitated particles were separated, washed with ethanol and deionized water several times to remove the organic contaminants and the surfactant. The particles were dried at $80^{\circ} \mathrm{C}$ for $48 \mathrm{~h}$ and were then calcinated at $450^{\circ} \mathrm{C}$ for $2 \mathrm{~h}$. It was found that the obtained nanocomposites contained highly and uniformly dispersed $\mathrm{Ag} / \mathrm{Cu}$ nanoparticles on the $\mathrm{TiO}_{2}$ surface. The maximum in the photocatalytic activity under visible light was observed for the sample containing $0.5 \mathrm{~mol} \%$ of $\mathrm{Cu}$ and $1.5 \mathrm{~mol} \%$ of $\mathrm{Ag}$.

The rate of phenol decomposition average was $2.41 \mu \mathrm{mol} \mathrm{dm}-3 \mathrm{~min}^{-1}$ and was higher than for $\mathrm{Ag} / \mathrm{Cu}-\mathrm{TiO}_{2}$ containing $1.5 \mathrm{~mol} \%$ of $\mathrm{Cu}$ and $0.5 \mathrm{~mol} \%$ of $\mathrm{Ag}$. It indicates that the presence of silver was more beneficial for visible light activation of $\mathrm{TiO}_{2}$ doped 
photocatalysts than a higher copper amount. The $\mathrm{Au} / \mathrm{Cu}-\mathrm{TiO}_{2}$ nanoparticles revealed lower photocatalytic activity compared to $\mathrm{Ag} / \mathrm{Cu}-\mathrm{TiO}_{2}$ photocatalysts containing the same metal amount loading on $\mathrm{TiO}_{2}$ surface The photocatalysts modified with silver revealed higher antimicrobial activity than pure $\mathrm{TiO}_{2}$ obtained in the microemulsion system or the samples containing only copper nanoparticles deposited on $\mathrm{TiO}_{2}$ surface. It indicated that silver possesses higher antimicrobial activity than copper nanoparticles prepared in the microemulsion system. The best antimicrobial activity revealed $\mathrm{Ag} / \mathrm{Cu}-\mathrm{TiO}_{2}$ with the highest silver amount average $6.5 \mathrm{~mol} \%$ and the sample $\mathrm{Ag} / \mathrm{Cu}-\mathrm{TiO}_{2}$ containing $1.5 \mathrm{~mol} \%$ of $\mathrm{Ag}$ and $0.5 \mathrm{~mol} \%$ of $\mathrm{Cu}$, which exhibited also the highest efficiency of phenol degradation under visible light.

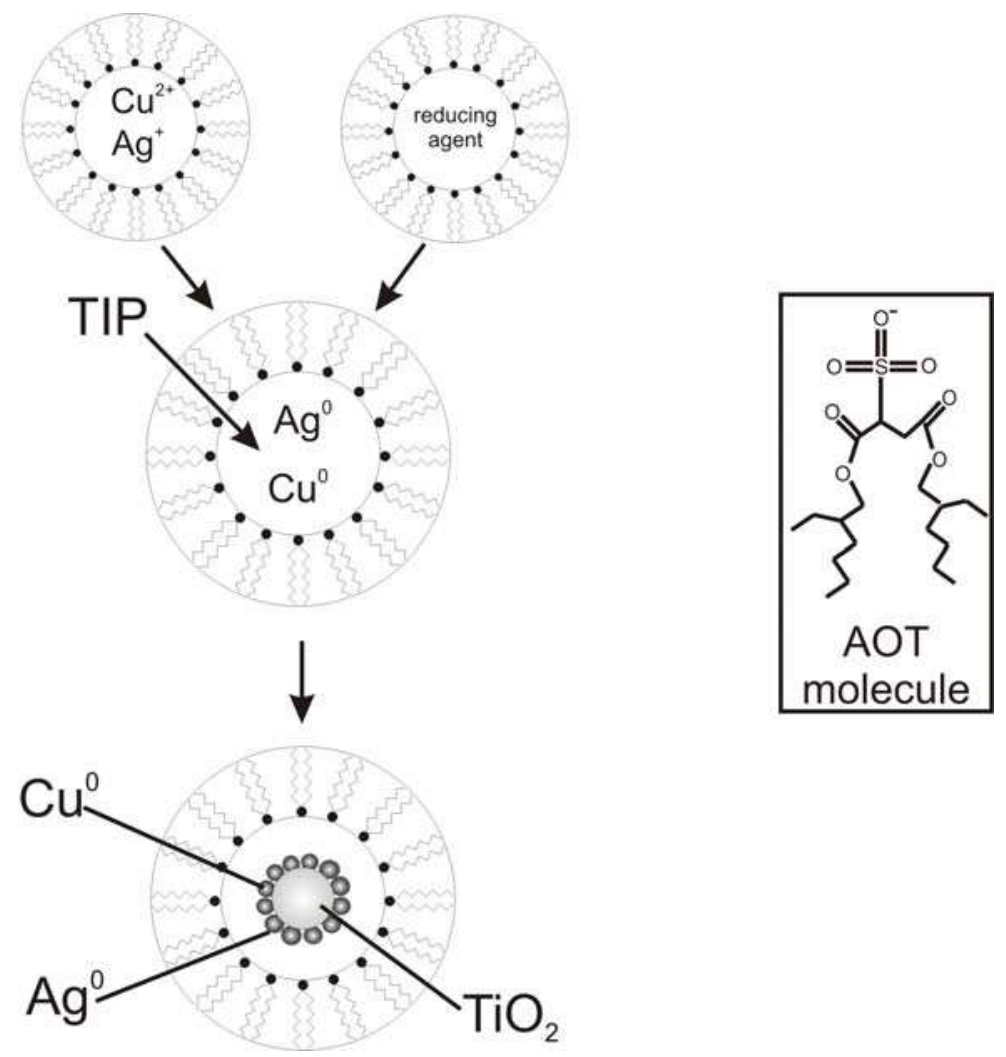

Fig. 4. Mechanism of the preparation method of $\mathrm{Ag} / \mathrm{Cu}$ modified titanium dioxide nanoparticles in W/O microemulsion (Zielińska-Jurek, 2010)

\section{Challenges in nanoparticles preparation using microemulsion as a template}

It has been shown that microemulsion as a liquid structure having a high surface area can be used as chemical nanoreactors to obtain a wide range of nanoparticles of different chemical nature, size and shape. However, recovery of the nanoparticles and their separation from 
the microemulsion system, as well as the recovery and recycling of the organic solvents remains a challenge. Conventional separation techniques such as ultracentrifugation, solvent evaporation, addition of a suitable solvent to cause phase separation or precipitation (ethanol, acetone, water) have been applied to recover nanoparticles from the W/O microemulsion system.

An interesting approach is the addition of $\mathrm{CO}_{2}$ as an antisolvent, since it provides an inexpensive, benign, nontoxic means to efficiently control the nanoparticles stability. Supercritical carbon dioxide exhibits a dielectric constant even lower than most organic solvents and can be used as non-toxic continuous phase in $\mathrm{W} / \mathrm{O}$ microemulsions (Hutton, 1998). Jonhston et al. have found that an ammonium carboxylate perfluoropolyether (PFPE) surfactant can be used for stabilization of microemulsions in supercritical $\mathrm{CO}_{2}$ (Jonhston et al., 1996). The PFPE-based microemulsion using supercritical $\mathrm{CO}_{2}$ as continous phase were subsequently used as nanoreactors for preparation of nanoparticles. Holmes et al. prepared $\mathrm{CdS}$ nanoparticles in PFPE-scCO 2 microemulsion at $45^{\circ} \mathrm{C}$ and 345 bar. The particle size was about $1.8 \mathrm{~nm}$ depending on the water to surfactant molar ratio $(W)$ (Holmes et al., 1999).

Dong et al. prepared CuS nanoparticles by mixing two separate water in carbon dioxide microemulsions stabilized using sodium salt of bis(2,2,3,3,4,4,5,5-octafluoro-1-pentyl)-2sulfosuccinate (AOT). The size of copper sulfide nanoparticles ranged from 4 to $6 \mathrm{~nm}$ (Dong et al., 2002). Wu et al. obtained $\mathrm{TiO}_{2}$ nanoparticles from its precursor titanium (IV) isopropoxide (TTIP) by a combination of supercritical fluid microemulsion and supercritical-drying techniques, in which TTIP hydrolized in reverse micelles $\left(\mathrm{H}_{2} \mathrm{O}\right.$ being surrounded by $\mathrm{CO}_{2}$ ) formed by surfactant Zonyl FSJ using a medium of supercritical carbon dioxide. $\mathrm{TiO}_{2}$ particles prepared in these systems have average size of about 2$7 \mathrm{~nm}$ (Wu et al., 2008). Ohde et al. reported that nanometer-sized silver and copper metal particles can be prepared by chemical reduction of $\mathrm{Ag}^{+}$and $\mathrm{Cu}^{2+}$ ions dissolved in the water core of water in supercritical fluid carbon dioxide microemulsion. Sodium cyanoborohydride and $N, N, N^{\prime}, N^{\prime}$-tetramethyl-p-phenylenediamine were used as reducing agents for preparation of metal nanoparticles in the microemulsion. They found that diffusion and distribution of the oxidized form of the reducing agent between the micellar core and supercritical $\mathrm{CO}_{2}$ appeared to be the rate-determining step for the formation of silver nanoparticles in this system.

Meziani et al. prepared silver nanoparticles in the Rapid Expansion of a Supercritical Solution into a Liquid SOLVent (RESOLV). Perfluorinated surfactant-stabilized water-in$\mathrm{CO}_{2}$ microemulsion was used to dissolve silver salt for the rapid expansion. An aqueous $\mathrm{AgNO}_{3}$ solution was added to the syringe pump followed by the addition of $\mathrm{PFPE}_{\mathrm{NH}}$ to result in a $\mathrm{W}$ value of 10 . After loading of $\mathrm{CO}_{2}$ to the pressure of 2500 psia, the mixture in the syringe pump was equilibrated with stirring for $2 \mathrm{~h}$. The rapid expansion was carried out at 4000 psia and $35^{\circ} \mathrm{C}$ through a 50 -micron fused silica capillary nozzle into a roomtemperature aqueous solution of $\mathrm{NaBH}_{4}$. The room-temperature receiving solution also contained PVP polymer $(5 \mathrm{mg} / \mathrm{mL})$ as a protection agent for the formed nanoparticles. Sodium hydroxide $(\mathrm{NaOH})$ was used to adjust the basicity of the room-temperature receiving solution. TEM images yielded average sizes of $3.1 \mathrm{~nm}$ (size distribution standard deviation $0.8 \mathrm{~nm}$ ) for the Ag nanoparticles in the supernatant and $10 \mathrm{~nm}$ (size distribution standard deviation $2 \mathrm{~nm}$ ) for the Ag nanoparticles in the precipitate (Meziani et al., 2005). Drawbacks of this technique are: the cost of using compressed $\mathrm{CO}_{2}$, a significant limitation 
of using $\mathrm{scCO}_{2}$ as continuous phase in microemulsion, low solubility of most solutes in neat supercritical $\mathrm{CO}_{2}$. Therefore, different co-surfactants (1-pentanol, 2-propanol) are often used to improve the solubility for hydrophilic components.

Another interesting approach is the use of photo-destructible surfactants as an attractive alternative to commonly used surfactants (AOT, TX-100, CTAB, SDS, NP-9, etc.) for stabilization of nanoparticles in $\mathrm{W} / \mathrm{O}$ microemulsion. A recent development in this field is the work of Eastoe, which demonstrated that photodestructible surfactants can be used to induce destabilization and phase separation in microemulsions. They studied the surface properties and UV-driven destruction of surfactant sodium 4-hexylphenylazosulfonate (Eastoe, 2006).

Vesperinal et al. obtained gold nanoparticles in water-in-oil -microemulsion with the addition of a photodestructible surfactant hexylphenylazosulfonate (C6PAS). They used UV light to induce destabilization of the microemulsion and flocculation of nanoparticles. The changes in dispersion stability occur owing to UV-induced breakdown of the hydrophilic hexylphenylazosulfonate into insoluble hydrophobic photoproducts (hexylbenzene and 4hexylphenol). They observed that in the photo-induced flocculate gold particle shapes were irregular and the particle sizes were in the range 15-120 nm (Vesperinal et al., 2007). By formulation of an appropriate mixture containing the photolyzable surfactant (sodium hexylphenylazosulfonate, C6PAS) and inert surfactants Salabat et al. photoflocculated/separated silica nanoparticles obtained in the organic solvent. During photodestruction of C6PAS non-surface-active oil-soluble hexylbenzene, and weakly surface-active hexylphenol (as well as sodium sulfur salts) were obtained. In this regard, it is an important goal for advanced projects to prepare size-controlled chemically clean nanoparticles with narrow size distribution (Salabat et al., 2007).

\section{Conclusions}

A large number of different nanomaterials have been prepared in water-in-oil microemulsions. The generated particle sizes can be controlled by the nanodroplet size of the inner phase of the microemulsion. The size of the particles can be controlled by:

- surfactant/co-surfactant type,

- solvent type,

- concentration of the reagents,

- ionic additives,

- water/surfactant molar ratio.

Among various preparation of nanoparticles methods, the use of microemulsion is an effective route for yielding a wide range of monodisperse nanoparticles of different size and shape. We have shown that the microemulsion method is preferable since it allows studying noble metal nanoparticles of different sizes deposited on the same titania material. Our results proved that the size of gold is the key-factor for high level activity under visible-light irradiation. However, titania material also plays a crucial role in obtaining material with high activity and the degree of influence of gold size on photoactivity (Zielińska-Jurek et al., 2010). The recovery of nanoparticles and their separation from the reaction medium is still a key step when using microemulsion system for preparation of nanocomposites. 


\section{References}

Ahmed, J.; Ramanujachary, K.V.; Lofland, S.E.; Furiato, A.; Gupta, G.; Shivaprasad, S.M. \& Ganguli, A.K. (2008). Bimetallic $\mathrm{Cu}-\mathrm{Ni}$ nanoparticles of varying composition $\left(\mathrm{CuNi}_{3}, \mathrm{CuNi}, \mathrm{Cu}_{3} \mathrm{Ni}\right)$. Colloids and Surfaces A: Physicochem. Eng. Aspects, Vol.331, pp. 206-212

Andersson, M.; Pedersen, J.,S. \& Palmqvist, A.E.C (2005). Silver Nanoparticle Formation in Microemulsions Acting Both as Template and Reducing Agent. Langmuir, Vol.21, pp. 11387- 11396

Arbain, R.; Othman, M. \& Palaniandy, S. (2011). Preparation of iron oxide nanoparticles by mechanical milling. Minerals Engineering, Vol.24, pp. 1-9

Bagwe, R.P. \& Khilar, K.C. (2000). Effects of Intermicellar Exchange Rate on the Formation of Silver Nanoparticles in Reverse Microemulsions of AOT, Langmuir, Vo.6, pp. 905-910

Bönnemann, H. \& Richards, R.M. (2001). Nanoscopic Metal Particles 2 Synthetic Methods and Potential Applications, Eur. J. Inorg. Chem. 245522480

Boutonnet, M.; Kizling, J.; Stenius, P. \& Maire, G. (1982). ThePreparation of monodisperse colloidal metal particles from microemulsions. Colloids Surf., Vol.5, pp. 209-225

Capek, I. (2004). Preparation of metal nanoparticles in water-in-oil (wyo) microemulsions. Advances in Colloid and Interface Science, Vol.110, pp. 49-74

Castillo, N.; Díaz Barriga, L.; Pérez, R.; Martínez-Ortiz, M.J. \& Gallardo, A.C. (2008). Structural and chemical characterization of pTX-pD1-X bimetallic nanoparticles supported on silica. Rev. Adv. Mater. Sci. Vol.18, pp. 72

Chen, D.; Liu, S.; Li, J.; Zhao, N.; Shi, C.; Du, X. \& Sheng, J. (2009). Nanometre Ni and core/shell $\mathrm{Ni} / \mathrm{Au}$ nanoparticles with controllable dimensions synthesized in reverse microemulsion, Journal of Alloys and Compounds, Vol.475, pp. 494-500

Chen, D.H. \& Chen, C.J. (2002). Formation and characterization of Au-Ag bimetallic nanoparticles in water-in-oil microemulsions. J. Mater. Chem., Vol.12, pp. 1557-1562

Chen, D.H., Yeh, J.J. \& Huang, T.C. (1999). Synthesis of Platinum Ultrafine Particles in AOT Reverse Micelles. Journal of Colloid and Interface Science, Vol.215, pp. 159-166

Chen, H.M.; Liu, R.S.; Jang, L.Y.; Lee, J.F. \& Hu, S.F. (2006). Characterization of core-shell type and alloy $\mathrm{Ag} / \mathrm{Au}$ bimetallic clusters by using extended X-ray absorption fine structure spectroscopy, Chemical Physics Letter, Vol.421, pp. 118-123

Chiang, C.L.; Hsu, M.B. \& Lai, L.B. (2004). Control of nucleation and growth of gold nanoparticles in AOT/Span80/isooctane mixed reverse micelles. Journal of Solid State Chemistry, Vol.177, pp. 3891-3895

Dong, X.; Potter, D. \& Erkey, C. (2002). Synthesis of CuS nanoparticles in water-in-carbon dioxide microemulsions, Ind. Eng. Chem. Res., Vol.41, pp. 4489-4493

Eastoe, J. (2006). Photo-destructible Surfactants in Microemulsions, Progr. Colloid. Polym. Sci., Vol.133, pp. 106-110

Fu, X. \& Qutubuddin, S. (2001). Synthesis of titania-coated silica nanoparticles using a nonionic water-in-oil microemulsion, Colloids and Surfaces A: Physicochemical and Engineering Aspects, Vol.179, pp. 65-70

Ganguli, A.K.; Ganguly, A. \& Vaidya S. (2010). Microemulsion-based synthesis of nanocrystalline materials, Chem. Soc. Rev., Vol.39,pp. 474-485

Ghosh, S.K.; Kundu, S. \& Pal, T. (2002). Evolution, dissolution and reversible generation of gold and silver nanoclusters in micelle by UV-activation. Bull. Mater. Sci. Vol.25, pp. 581-582 
Hayashi, H. \& Hakuta, Y. (2010). Hydrothermal Synthesis of Metal Oxide Nanoparticles in Supercritical Water. Materials, Vol.3, pp. 3794-3817

Holmes, J. D.; Bhargava, P. A.; Korgel, B. A. \& Johnston, K. P. (1999). Synthesis of cadmium sulfide $\mathrm{Q}$ particles in water-in- $\mathrm{CO}_{2}$ microemulsions. Langmuir,Vol.15, pp. 6613-6615

Hong, S.S.; Sig Lee M. \& Lee, G.D. (2003). Photocatalytic decomposition of $p$-nitrophenol over titanium dioxide prepared by reverse microemulsion method using nonionic surfactants with different hydrophilic groups React. Kinet. Catal. Lett., Vol.80, pp 145-151

Husein, M.M. \& Nassar, N.N. (2008). Nanoparticle Preparation Using the Single Microemulsions Scheme. Current Nanoscience, Vol.4, pp 370-380

Inaba, R.; Fukahori, T.; Hamamoto, M. \& Ohno, T. (2006). Synthesis of nanosized $\mathrm{TiO}_{2}$ particles in reverse micelle systems and their photocatalytic activity for degradation of toluene in gas phase J. Mol. Catal. A: Chem. Vol.260, pp. 247-254.

Jang, J., Yoon, H., (2003) Facile fabrication of polypyrrole nanotubes using reverse microemulsion polymerization Chem. Commun. Vol. 6, pp. 720-721

Jang, J., Yoon, H., (2005) Formation mechanism of conducting polypyrrole nanotubes in reverse micelle systems, Langmuir Vol. 21, pp. 11484-11489

Johnston, K. P.; Harrison, K. L.; Clarke, M. J.; Howdle, S. M.; Heitz, M. P.; Bright, F. V.; Carlier, C. \& Randolph, T. W. (1999). Water in- carbon dioxide microemulsions: An environment for hydrophiles including proteins. Science, Vol.271, pp. 624

Krauel, K.; Davies, N.M.; Hook, S. \& Rades, T. (2005). Using different structure types of microemulsions for the preparation of poly(alkylcyanoacrylate) nanoparticles by interfacial polymerization. J. Controlled Release, Vol.106, pp. 76-87

Kumar, P.; Pillai, V. \& Shah, D.O. (1993). Preparation of Bi-Pb-Sr-Ca-Cu-O oxide superconductors by coprecipitation of nanosize oxalate precursor powders in the aqueous core of water-in-oil microemulsions Appl. Phys. Lett., Vol.62, pp. 765-768

Lee, M., S.; Park, S.S., Lee, G.D., Ju, C.S. \& Hong, S.S. (2005). Synthesis of $\mathrm{TiO}_{2}$ particles by reverse microemulsion method using nonionic surfactants with different hydrophilic and hydrophobic group and their photocatalytic activity. Catal Today, Vol.101, pp. 283-290

Li, G.L. \& Wang, G.H. (1999). Synthesis of nanometer-sized $\mathrm{TiO}_{2}$ particles by a microemulsion method. Nanostructured Materials, Vol.11, pp. 663-668

Lisiecki, I. \& Pileni, M.P. (1995). Copper Metallic Particles Synthesized "in Situ" in Reverse Micelles: Influence of Various Parameters on the Size of the Particles, J. Phys. Chem., Vol.99, pp. 5077-5082

Lopez-Quintela, M.A. (2003). Synthesis of nanomaterials in microemulsions: formation mechanism and growth control. Curr. Opin. Coll. Int. Sci. Vol.8, pp. 137-144

Meziania, M.J.; Pathaka, P.; Beachama, F.; Allardb, L.F. \& Sun, Y-P. (2005). Nanoparticle formation in rapid expansion of water-in-supercritical carbon dioxide microemulsion into liquid solution, J. of Supercritical Fluids, Vol. 34, pp. 91-97

Mohanty, U.S. (2011). Electrodeposition: a versatile and inexpensive tool for the synthesis of nanoparticles, nanorods, nanowires, and nanoclusters of metals, J. Appl. Electrochem., Vol. 41, pp. 257-270

Mori, Y.; Okastu Y. \& Tsujimoto, Y. (2001). Titanium Dioxide Nanoparticles Produced in Water-in-oil Emulsion. J. Nanopart. Res. Vol. 3, pp. 219-225 
Pal, A., Shah, S. \& Devi, S. (2007a). Preparation of silver, gold and silver-gold bimetallic nanoparticles in W/O microemulsion containing TritonX-100, Colloids and Surfaces A: Physicochem. Eng. Aspects, Vol.302, pp. 483-487

Pal, A., Shah, S. \& Devi, S. (2007b). Synthesis of Au, Ag and Au-Ag alloy nanoparticles in aqueous polymer solution, Colloid Surface A, Vol.302, pp. 51-57

Pérez-Tijerina, E.; Gracia Pinilla, M.; Mejía-Rosales, S.; Ortiz-Méndez,U., Torres, A. \& JoséYacamán, M. (2008). Highly size-controlled synthesis of Au/Pdnanoparticles by inert-gas condensation, Faraday Discuss., Vol.138, pp. 353-362

Petitt, C.; Lixonf, P. \& Pileni M.P. (1993). In Situ Synthesis of Silver Nanocluster in AOT Reverse Micelles. J. Phys. Chem., Vol.97, pp. 12974-12983

Pinna, N.; Weiss, K.; Sack-Kongehl, H.; Vogel, W.; Urban, J. \& Pileni, M.P. (2001). Triangular CdS Nanocrystals: Synthesis, Characterization, and Stability. Langmuir, Vol.17, pp 7982-7987

Qian, L. \& Yang, X. (2005). Preparation and characterization of $\mathrm{Ag}(\mathrm{Au})$ bimetallic core-shell nanoparticles with new seed growth method, Colloid Surface A, Vol.260, pp. 79-85

Salabat, A.; Eastoe, J.; Vesperinas, A.; Tabor, R.F. \& Mutch, K.J. (2008). Photorecovery of Nanoparticles from an Organic Solvent. Langmuir, Vol.24, pp. 1829-1832

Sanchez-Dominguez, M.; Boutonnet, M. \& Solans, C. (2009). A novel approach to metal and metal oxide nanoparticle synthesis: the oil-in-water microemulsion reaction method, J Nanopart Res, Vol.11, pp. 1823-1829

Sarkar, D.; Tikku, S.; Thapar, V.; Srinivasa, R.S. \& Khilar, K.C. (2011). Formation of zinc oxide nanoparticles of different shapes in water-in-oil microemulsion, Colloids and Surfaces A: Physicochemical and Engineering Aspects, Vol.381, pp. 123-129

Solanki, J.N. \& Murthy, Z.V.P. (2010). Highly monodisperse and sub-nano silver particles synthesis via microemulsion technique, Colloids and Surfaces A: Physicochem. Eng. Aspects, Vol.359, pp. 31-38

Solanki, J.N.; Sengupta, R. \& Murthy, Z.V.P. (2010). Synthesis of copper sulphide and copper nanoparticles with microemulsion method, Solid State Sciences, Vol.12, pp. 1560-1566

Sonawane, R.,S. \& Dongare, M.,K. (2006). Sol-gel synthesis of $\mathrm{Au} / \mathrm{TiO}_{2}$ thin films for photocatalytic degradation of phenol in sunlight, J. Mol. Cat. A,Vol.243, pp. 68-76

Song, K.C.; Lee; S.M., Park; T.S. \& Lee, B.S. (2009). Preparation of colloidal silver nanoparticles by chemical reduction method. Korean J. Chem. Eng. Vol.26, pp. 153-155

Spirin, M.G.; Brichkin, S.B. \& Razumov, V.F. (2005). Synthesis and Stabilization of Gold Nanoparticles in Reverse Micelles of Aerosol OT and Triton X-100. Colloid J. Vol.67, pp. $485-490$

Uskokovic, V. \& Drofenik, M. (2007). Reverse micelles: inert nano-reactors or physicchemically active guides of the capped reactions. Adv. Coll. Interf. Sci., Vol.133, pp. 23-34

Vesperinas, A.; Eastoe, J.; Jackson, S. \& Wyatt, P. (2007). Light-induced flocculation of gold nanoparticles. Chem. Commun., Vol. , pp. 3912-3914

Wongwailikhit, K. \& Horwongsakul, S. (2011). The preparation of iron (III) oxide nanoparticles using W/O microemulsion. Materials Letters, Vol.65, pp. 2820-2822

Wu, C.I.; Huang, J.W.; Wen, Y.L.; Wen, S.B.; Shen, Y.H. \& Yeh, M.Y. (2005). Preparation of $\mathrm{TiO}_{2}$ nanoparticles by supercritical carbon dioxide. Materials Letters, Vol.62, pp.1923-1926 
Xia, L.; Hu, X.; Kang, X.; Zhao, H.; Sun, M. \& Cihen, X. (2010). A one-step facile synthesis of Ag-Ni core-shell nanoparticles in water-in-oil microemulsions. Colloids and Surfaces A: Physicochem. Eng. Aspects, Vol.367, pp. 96-101

Zhang, W.; Qiao, X.; Chen, J. \& Wang, H. (2006). Preparations of silver nanoparticles in water-in-oil AOY reverse micells. J. Colloid Interf Sci, Vol.302, pp. 370-373

Zhang, W.; Qiao, X. \& Chen, J. (2007). Synthesis of silver nanoparticles - Effects of concerned parameters in water/oil microemulsion. Mater. Sci. Eng. B, Vol.142, pp. 1-15

Zhang, W.; Qiao, X.; Chen, J. \& Chen Q. (2008). Self-assembly and controlled synthesis of silver nanoparticles in SDS quaternary microemulsion. Materials Letters, Vol.62, pp. 1689-1692

Zielińska-Jurek, A.; Walicka, M.; Tadajewska, A.; Łącka, I.; Gazda, M. \& Zaleska, A. (2010). Preparation of Ag/Cu-doped titanium (IV) oxide nanoparticles in W/O microemulsion. Physicochem. Probl. Miner. Process. Vol.45, pp. 113-126

Zielińska-Jurek, A.; Kowalska, E.; Sobczak, J.W.; Lisowski, W.; Ohtani, B. \& Zaleska, A. (2011). Preparation and characterization of monometallic ( $\mathrm{Au}$ ) and bimetallic $(\mathrm{Ag} / \mathrm{Au})$ modified-titania photocatalysts activated by visible light. Appl. Catal. B: Environ., Vol.101, pp.504-514 


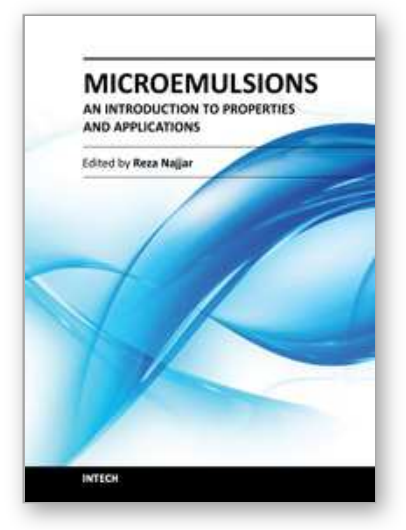

\author{
Microemulsions - An Introduction to Properties and Applications \\ Edited by Dr. Reza Najjar
}

ISBN 978-953-51-0247-2

Hard cover, 250 pages

Publisher InTech

Published online 16, March, 2012

Published in print edition March, 2012

The rapidly increasing number of applications for microemulsions has kept this relatively old topic still at the top point of research themes. This book provides an assessment of some issues influencing the characteristics and performance of the microemulsions, as well as their main types of applications. In chapter 1 a short introduction about the background, various aspects and applications of microemulsions is given. In Part 2 some experimental and modeling investigations on microstructure and phase behavior of these systems have been discussed. The last two parts of book is devoted to discussion on different types of microemulsion's applications, namely, use in drug delivery, vaccines, oil industry, preparation of nanostructured polymeric, metallic and metal oxides materials for different applications.

\title{
How to reference
}

In order to correctly reference this scholarly work, feel free to copy and paste the following:

Anna Zielińska-Jurek, Joanna Reszczyńska, Ewelina Grabowska and Adriana Zaleska (2012). Nanoparticles Preparation Using Microemulsion Systems, Microemulsions - An Introduction to Properties and Applications, Dr. Reza Najjar (Ed.), ISBN: 978-953-51-0247-2, InTech, Available from:

http://www.intechopen.com/books/microemulsions-an-introduction-to-properties-andapplications/nanoparticles-preparation-using-microemulsion-systems

\section{INTECH}

open science | open minds

\author{
InTech Europe \\ University Campus STeP Ri \\ Slavka Krautzeka 83/A \\ 51000 Rijeka, Croatia \\ Phone: +385 (51) 770447 \\ Fax: +385 (51) 686166 \\ www.intechopen.com
}

\author{
InTech China \\ Unit 405, Office Block, Hotel Equatorial Shanghai \\ No.65, Yan An Road (West), Shanghai, 200040, China \\ 中国上海市延安西路65号上海国际贵都大饭店办公楼 405 单元 \\ Phone: +86-21-62489820 \\ Fax: +86-21-62489821
}


(C) 2012 The Author(s). Licensee IntechOpen. This is an open access article distributed under the terms of the Creative Commons Attribution 3.0 License, which permits unrestricted use, distribution, and reproduction in any medium, provided the original work is properly cited. 